\title{
Synthesis and characterization of hydroxyapatite contain chromium
}

\author{
Samira M. Sallam ${ }^{1 *}$, Khairi M. Tohami ${ }^{2}$, Abdelsattar M. Sallam ${ }^{3}$, Lotfi I. Abo Salem ${ }^{1}$, \\ Faten Adel Mohamed ${ }^{1}$ \\ ${ }^{1}$ Department of Physics, Science College, Benha University, Banha, Egypt; ${ }^{*}$ Corresponding Author: drsmsallam@yahoo.com \\ ${ }^{2}$ Department of BioPhysics, Science College, El Azhar University, Cairo, Egypt \\ ${ }^{3}$ Department of BioPhysics, Science College, Ain Shams University, Cairo, Egypt
}

Received 21 June 2012; revised 15 August 2012; accepted 26 August 2012

\begin{abstract}
Hydroxy apatite (HA) is a biocompatible material used as bone-substitute materials in both orthopedics and dentistry due to its excellent osteoconductive and chemical composition similar to that of the inorganic part of bone in comparison with other implant materials. HA (S1) and $\mathrm{Cr}$ loaded hydroxy apatite (S2, S3, S4 and S5) of different chromium concentrations have been prepared. many techniques used to analyze the changes occurred due to the substitution. The XRD (X-ray diffraction) and FTIR (Fourier transform infrared radiation) spectroscopy were used as analytical techniques for the prepared HA and $\mathrm{Cr}$ loaded HA. The effect of the heat treatment on structural change of the samples was examined by DTA. It was found that all the samples have the same crystalline structure. The crystallinity of the samples decreased as the chromium ions concentration increase.
\end{abstract}

Keywords: Component; Formatting; Style; Styling; Insert

\section{INTRODUCTION}

Substitution of foreign ions in the crystal of $\mathrm{CaP}_{\mathrm{s}}$ occurs frequently. In particular, the high stability and flexibility of apatite structure acouts for the great variety of possible cationic and anionic substitution. Several ions have been reparted to be replace, at least partially, $\mathrm{Ca}$ ions in the structure of HA. In particular, ions with smaller ionic radius than $\mathrm{Ca}^{2+}$, usually stabilize the crystal lattice [1].

Hydroxy apatite is the main inorganic components of living hard tissues. Due to its excellent biocompatability, it is regarded as an important bioceramic material in artificial replacement of bones and teeth. The samples of commercial HA with different addition of Lithium ions produces an increase in microhardness of HA.

Also, an addition of $0.2 \%$ of $\mathrm{Li}$ ions produces the necessary liquid phases to improve the microstructure [2]. zinc-containing tricalcium phosphate is biocompatible and bioactive, and functioned as an effective zinc carriers. The composite ceramic of Zn TCP and HA P enhanced osteoblastic cell proliferation and differentiation in-vitro. Also, it is promising biomaterial that has pharmaceutical effect of promoting bone formation [3].

Chromium-loaded calcium-hydroxyapatite prepared utilizing the exchange properties of apatite, HA nanoparticles have been investigated by using XRD, FTIR, Chemical analysis and laser diffraction method. They found that the synthesized apatite is calcium deficient and that their specific surface area decrease slightly by increasing the $\mathrm{Cr}^{3+}$ loading. When increasing the initial $\mathrm{Cr}^{3+}$ amount in the solution, the $\mathrm{Ca}^{2+}$ atomic ratio diminishes linearly and the $\mathrm{Cr}^{3+}$ atomic ratio increases which indicates that Calcium ions are substituted by chromium ions in CaHAp crystal. The XRD patterns of $\mathrm{Cr}(\mathrm{x}) / \mathrm{CaHAp}$ are similar to that of pure calcium-hydroxyapatite (JPCDS no. 00-0240033) and no peak of crystalline chromia was detected in the diffractograms.

Both a and c lattice parameters decrease very slightly upon chromium addition. Concomitantly, the unit cell volume of the lattice undergoes a small contraction which seems to indicate some incorporation of chromium into the CaHAp framework and there is no significant difference is detected between the FTIR spectra of pure CaHAp and $\mathrm{Cr}$ loaded CaHAp [4].

The investigation of the effects of $\mathrm{Co}^{2+}, \mathrm{Cr}^{3+}$ and $\mathrm{Ni}^{2+}$ on hydroxyapatite (HA) growth in vitro, using carboxy methylated poly(2-hydroxyethyl methacrylate) (pHEMA) as a biomaterial for calcification. We have demonstrated that metal ions reduced the quantity of mineral formed at the surface of the polymer and decreased the ratio $\mathrm{Ca} / \mathrm{P}$ by 1.12-, 1.05- and 1.08-fold for $\mathrm{Cr}^{2+}, \mathrm{Cr}^{3+}$ and $\mathrm{Ni}^{2+}$ respectively. Furthermore, the size of calcospherites was 
significantly increased in the metal-doped HA compared to the controls, indicating a possible effect of metal ions on the crystal lattice. Indeed, the presence of metal ions increased the crystal size as well as the crystallinity of HA and reduce the lattice parameter $\mathrm{c}$ of the HA framework. The information obtained from this work suggests that the quality of the mineral around metallic implants could be altered. However, further investigation should be conducted to further elucidate the effects of metal incorporation on bone mineral and the functional consequences [5].

The present work is concerned and interested in seaking for a biomaterial suitable, biophysically and physiologically, to meet beneficial medical uses and applications by synthesize calcium hydroxyl apatite. This preparation depend on the substitution of calcium ions in hydroxyapatite crystal by chromium ions to become calcium deficient apatite which improve the chemical and physical properties of the HA.

\section{MATERIALS and METHODS}

A wet precipitated method used to prepare calcium phosphate bioceramic (S1) and the other samples are calcium phosphate bioceramic doped by chromium nitrate of different concentrations (S2, S3, S4and S5) of [0.005, $0.01,0.02$ and 0.03 mole] of $\mathrm{Cr}\left(\mathrm{NO}_{3}\right)_{2} \cdot 9 \mathrm{H}_{2} \mathrm{O}$ respectively.

\section{Calcium Phosphate Bioceramic Samples}

Calcium phosphate bioceramic powder was prepared by an aqueous precipitation technique using 0.16 Mole of calcium nitrate titrahydrate $\left[\mathrm{Ca}\left(\mathrm{No}_{3}\right)_{2} \cdot 4 \mathrm{H}_{2} \mathrm{O}\right]$ as a source of calcium which dissolving in one liter of de-ionized water and 0.096 Mole of di-ammonium hydrogen orthophosphate $\left[\left(\mathrm{NH}_{4}\right)_{2} \mathrm{HPO}_{4}\right]$ as a source of phosphorous which dissolving in one liter of de-ionized water. For preparing the $\mathrm{Cr}$ loaded HA samples, [0.005, 0.01, 0.02 and 0.03 mole] of $\mathrm{Cr}\left(\mathrm{No}_{3}\right)_{2} \cdot 9 \mathrm{H}_{2} \mathrm{O}$ dissolved with $\mathrm{Ca}\left(\mathrm{NO}_{3}\right)_{2} \cdot 4 \mathrm{H}_{2} \mathrm{O}$ in one liter of de-ionized water.

The $\mathrm{pH}$ of both solutions was adjusted to about 10 by the addition of a dilute $\mathrm{NH}_{4} \mathrm{OH}$ solution proper strength. Following $\mathrm{pH}$ adjustment, 0.096 Mole $\left[\left(\mathrm{NH}_{4}\right)_{2} \cdot \mathrm{HPO}_{4}\right]$ solution was fed from a burette, in a dropwise manner (2 $5 \mathrm{ml} / \mathrm{min}$ ), into a stirred solution of $0.16 \mathrm{M}\left[\mathrm{Ca}\left(\mathrm{No}_{3}\right)_{2} \cdot 4 \mathrm{H}_{2} \mathrm{O}\right]$ heated to $60^{\circ} \mathrm{C}$ on a hot plate, during this reaction $\mathrm{PH}$ must maintain constant at 10 by the addition of a dilute $\mathrm{NH}_{4} \mathrm{OH}$ solution or $\mathrm{HNO}_{3}$.

After mixing, the solution was aged and vigorously stirred at its boiling point for about $2 \mathrm{~h}$ in a sealed container. The HA precipitates were recovered from the solution by sucking filtration and washed three times with de-ionized water, followed by drying at $100^{\circ} \mathrm{C}$ overnight. The powder was dis-agglomerated by gently grinding.

\section{CHARACTERIZATION}

The crystallographic properties of the precursor powder calcium-phosphate bioceramics without sintering (asdry) were investigated by (D8 ADVANCE, BRUKER, Axs Germany) diffractometer, using monochromatic CuKal radiation $(\lambda=1.54 \AA)$ with scanning rate $0.1^{\circ}$ in the $2 \theta$ ranging from $10^{\circ}$ to $80^{\circ}$ step time $1 \mathrm{sec}$. Purity of the calcium-phosphate bioceramic without sintering (asdry) was tested by FTIR spectral analysis.

Each sample used for infrared spectroscopic analysis was prepared according to standard procedure by mixing about $2.00 \mathrm{mg}$ of powder sample with $200 \mathrm{mg}$ of $\mathrm{KBr}$, which was subsequently pressed into pellet in an evacuated die.

All the spectra were measured by using (Model 1600, Perkin-Elmer) infrared spectrometer with a resolution of $4.00 \mathrm{~cm}-1$ at room temperature, which covers the wave number range of $4000-400 \mathrm{~cm}-1$ to evaluate the function group of the samples. The sample with the weight of $20 \mathrm{mg}$ were analyzed by DTA measuring system (SETARAM, LabsysTM, TG-DSC1600 France) using $\alpha-\mathrm{Al}_{2} \mathrm{O}_{3}$ powders as a reference material. The sample and the reference material were heated in air from room temperature to $1100^{\circ} \mathrm{C}$ in argon at heating rate of $10^{\circ} \mathrm{C} / \mathrm{min}$.

\section{RESULTS and DISCUSSION}

It was noticed that, The XRD patterns of $\mathrm{Cr}(\mathrm{x}) / \mathrm{CaHAp}$ are similar to that of pure calcium-hydroxyapatite JCPDS card No. (9-432) and no peak of crystalline chromia was detected in the diffractograms as shown in Figure 1.

The XRD analysis of the as prepared calcium-phosphate bioceramic powder, revealed that, it was a hexagonal shape and no secondary phases besides the apatitic phase. The evaluated degrees of crystallinity for these samples are given in the Table 1, show the degree of

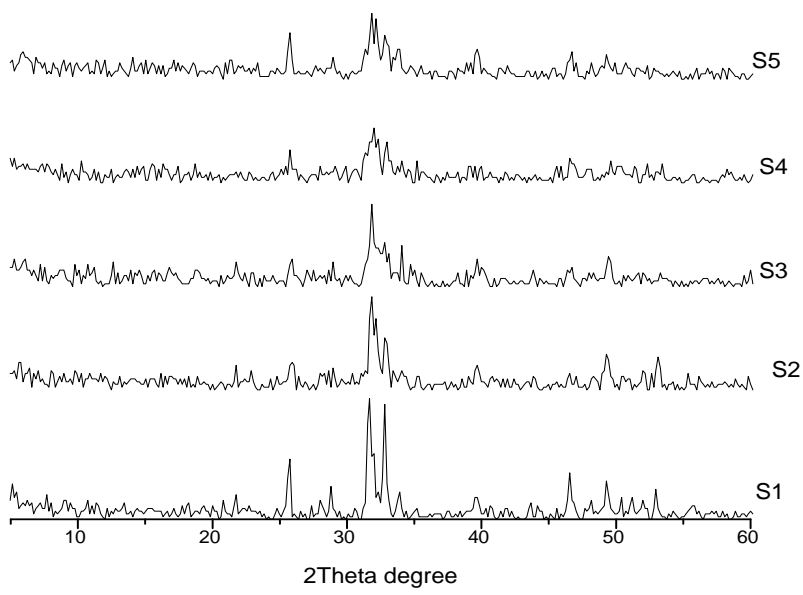

Figure 1. The XRD pattern of prepared $\mathrm{HA}(\mathrm{S} 1)$ and $\mathrm{Cr}$ loaded hydroxyl apatite (S2, S3, S4 and S5) of concentrations [0.005, $0.01,0.02$ and 0.03 mole] of $\mathrm{Cr}\left(\mathrm{NO}_{3}\right)_{2} \cdot 9 \mathrm{H}_{2} \mathrm{O}$ respectively. 
Table 1. The degree of crystallinity of pure calcium hydroxyl apatite (S1) and HA doped by chromium ions (S2, S3, S4 and S5) of different chromium concentrations [0.005, 0.01, 0.02 and 0.03 mole] respectively.

\begin{tabular}{cc}
\hline Crystallinity $\left(X_{c}\right)(\%)$ & Materials \\
\hline 76.12 & $\mathrm{~S} 1$ \\
69.87 & $\mathrm{~S} 2$ \\
68.88 & $\mathrm{~S} 3$ \\
68.88 & $\mathrm{~S} 4$ \\
63.43 & $\mathrm{~S} 5$ \\
\hline
\end{tabular}

crystallinity $\left(X_{c}\right)$ of S1, S2, S3, S4 and S5 depends on the presence of chromium ions contents thus: upon chromium addition the crystallinity of the samples decreased as the chromium ions concentrations increase. This is may be due to the substitution of $\mathrm{Ca}$ ions by the $\mathrm{Cr}$ ions which cause deformation in the lattice structure of the HA crystal.

The fraction of crystalline phase $\left(X_{c} \%\right)$ in bioceramic powders can be evaluated by the following equation [6]:

$$
X_{c}=1-\frac{V_{112 / 300}}{I_{300}}
$$

where $X_{c} \%$ is the crystallinity degree, $V_{112 / 300}$ is the intensity of the hollow between (112) and (300) diffraction peaks, $I_{300}$ is the intensity of (300) diffraction peak.

The crystallite size was calculated from the broadening in the XRD pattern. According to the Scherrer's equation:

$$
L_{h k l}=\frac{K \lambda}{\beta \cos \theta_{h k l}}
$$

The values of crystal size of the samples and FWHM were listed in Table 2. We notice that the crystallite size decrease with increasing FWHM. The evaluated degrees of crystallite size at the main peak (211) show the crystallite size of S1, S2, S3, S4 and S5 depends on the presence of chromium ions contents thus: upon chromium addition, the crystallite size decreased due to increases of the lattice disorder as a result of the presence of chromium ions in the prepared sample. The crystallite size began to increase again as a result of increasing the amount of chromium ions. This result is in agreement with the fact that the crystallite size is decreased by doping small amount of $\mathrm{Cr}^{3+}$ ions and increased with increasing the amount of $\mathrm{Cr}^{3+}$ ions [7].

The lattice parameters of CaHAp and $\mathrm{Cr} / \mathrm{CaHAp}$ shows that both (a) and (c) parameters decrease very slightly upon chromium addition at S2 and S3, and also the volume of the lattice undergoes a small contraction as shown in Table 3. This behavior is due to the fact that
Table 2. The crystallite size of prepared HA (S1) and HA doped by chromium ions (S2, S3, S4 and S5) of concentrations [0.005, $0.01,0.02$ and 0.03 mole] of $\mathrm{Cr}\left(\mathrm{NO}_{3}\right)_{2} \cdot 9 \mathrm{H}_{2} \mathrm{O}$ respectively.

\begin{tabular}{ccc}
\hline & $\begin{array}{c}\text { Full width at half maximum } \\
\beta \text { (radial) } \beta 211\end{array}$ & $\begin{array}{c}\text { Crystallite size, } L(\mathrm{~nm}) \text { by } \\
\text { Scherrer's equation }\end{array}$ \\
\hline S1 & 0.0045 & 35.57 \\
S2 & 0.0099 & 16.19 \\
S3 & 0.0082 & 19.56 \\
S4 & 0.0070 & 22.91 \\
S5 & 0.0038 & 42.43 \\
\hline
\end{tabular}

Table 3. The lattice parameters and unit cell volume of HA (S1) and HA doped by chromium ions of [0.005, 0.01, 0.02 and 0.03 mole] of $\mathrm{Cr}\left(\mathrm{NO}_{3}\right)_{2} \cdot 9 \mathrm{H}_{2} \mathrm{O}(\mathrm{S} 2, \mathrm{~S} 3, \mathrm{~S} 4$ and $\mathrm{S} 5)$ samples respectively.

\begin{tabular}{cccc}
\hline & $\begin{array}{c}\text { Averge of lattice } \\
\text { parameter }(\mathrm{a}) \mathrm{a}=\mathrm{b}\end{array}$ & $\begin{array}{c}\text { Averge of lattice } \\
\text { parameter }(\mathrm{c})\end{array}$ & $\begin{array}{c}\text { Unit cell } \\
\text { volume } \\
\left(\mathrm{A}^{3}\right)\end{array}$ \\
\hline S1 & 9.413 & 6.887 & 528.56 \\
S2 & 9.312 & 6.865 & 515.63 \\
S3 & 9.219 & 6.854 & 504.58 \\
S4 & 9.325 & 6.860 & 516.64 \\
S5 & 9.386 & 6.882 & 525.14 \\
\hline
\end{tabular}

The ionic radii of $\mathrm{Cr}(0.69 \AA \dot{\AA})$ is smaller than the radius of $\mathrm{Ca}(0.99 \AA \AA)$ [8,9], which is in agreement with the observed decrease in lattice parameters for Cr_HA then it observed that the lattice parameter and the volume began to increase again at $\mathrm{S} 4$ and $\mathrm{S} 5$, and this is may be due to the crowded of the Cr ions in the HA crystal.

The change in the lattice parameters of Cr_HA clearly demonstrated that $\mathrm{Cr}$ ions were structurally incorporated into HA crystals, they did not just cover the surface of the crystals.

FTIR for the prepared samples show that there is no significant difference is detected between the FTIR spectra of pure CaHAp [Figure 2, spectrum S1] and the samples doped by chromium ions [Figure 2, spectra S2, S3, $\mathrm{S} 4$ and S5]. The two bands at 3568 and $633 \mathrm{~cm}^{-1}$ are assigned to the stretching and bending modes of $\mathrm{OH}$ groups, respecttively. The presence of $\left(\mathrm{PO}_{4}\right)^{3-}$ is attested by 1) the P-O stretching modes appearing at $1095,1035 \mathrm{~cm}^{-1}$ $\left(\mathrm{v}_{3}\right)$ and $\left.965 \mathrm{~cm}^{-1}\left(\mathrm{v}_{1}\right) ; 2\right)$ the O-P-O bending modes observed at $605,567 \mathrm{~cm}^{-1}\left(\mathrm{v}_{4}\right)$ and $468 \mathrm{~cm}^{-1}\left(\mathrm{v}_{2}\right)$ [10]. Besides those typical bands of CaHAp, two bands at 1644 $\mathrm{cm}^{-1}$ and around $3439 \mathrm{~cm}^{-1}$ are due to adsorbed molecular water, whereas two small peaks at 1423 and 1455 $\mathrm{cm}^{-1}$ indicate the presence of carbonate group. In addition, the shoulder at $879 \mathrm{~cm}^{-1}$ is assigned to $\left(\mathrm{HPO}_{4}\right)^{2}$ groups formed upon reaction of some surface $\left(\mathrm{PO}_{4}\right)^{3-}$ with water.

The introduction of $\mathrm{Cr}$ in the samples [Figure 2, spec- 
tra S2, S3, S4 and S5] leads to the decrease of the intensity of the band at $3568 \mathrm{~cm}^{-1}$, assigned to the stretching vibrations of structural $\mathrm{OH}$ groups located in apatite tunnels. This intensity decrease may be ascribed to the dehydroxylation which might accompany the formation procedure, at high loadings of different chromium species $[11,12]$.

The effect of the heat treatment on structural change of the samples was examined. DTA curve of S1 as-dried powder which was heated to $1100^{\circ} \mathrm{C}$ is presented in Figure 3. The first endothermic region range from $71.99^{\circ} \mathrm{C}$ to $282.30^{\circ} \mathrm{C}$ with a peak at about $85.27^{\circ} \mathrm{C}$ and at 282.07 which corresponds to the dehydration of the precipitating complex. The DTA curve of calcium-phosphate bioceramics sample shows an exothermic transition in the range $333.81^{\circ} \mathrm{C}-363.33^{\circ} \mathrm{C}$. Very probably it is the crys-
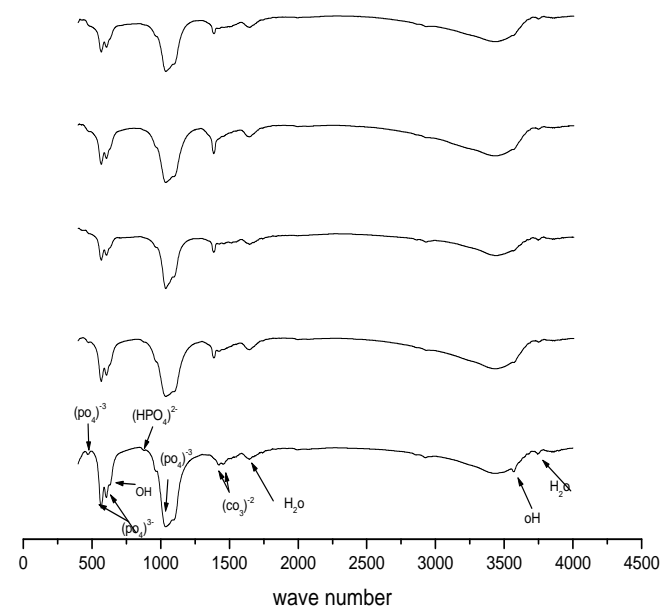

Figure 2. FTIR peaks of prepared HA (S1) and HA doped by chromium ions (S2, S3, S4 and S5) of concentrations [0.005, 0.01, 0.02 and 0.03 mole] of $\mathrm{Cr}\left(\mathrm{NO}_{3}\right) 2 \cdot 9 \mathrm{H}_{2} \mathrm{O}$ respectively.

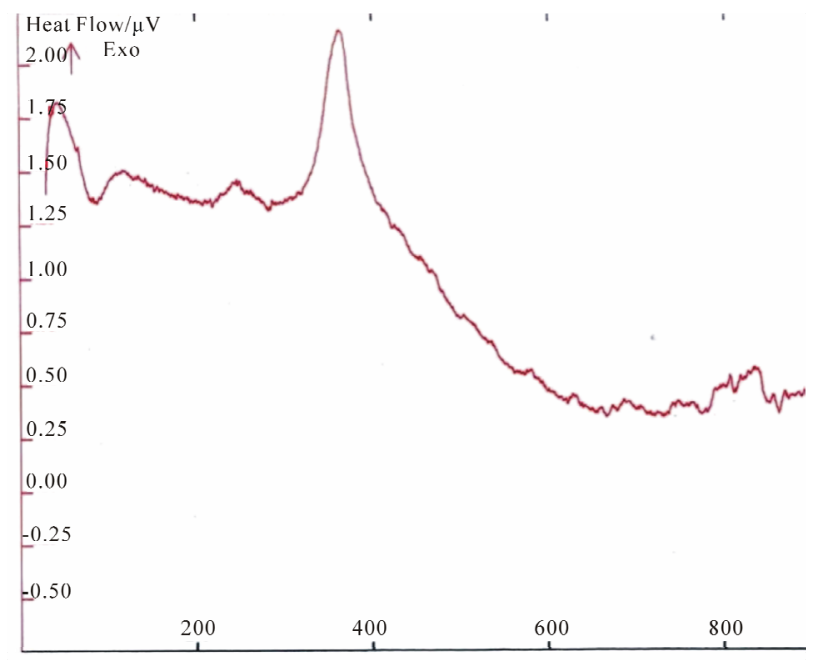

Figure 3. DTA curve of the prepared hydroxyl apatite sample (S1) as-dried powder heated to $1100^{\circ} \mathrm{C}$. tallization temperature of the sample, this peak is due to the heat of crystallization of the amorphous part in these sample, because these materials are not completely crystalline but contains small quantities of amorphous calcium phosphate. This exothermic peak varies according to the crystallinity of the sample.

\section{CONCLUSION}

This study indicate that chromium ions can be incorporated into the hydroxyapatite crystal during mineralization FTIR spectroscopy gives us functional groups of calcium-phosphate apatite and its substitution enters during the preparation depending on the variation of $\mathrm{Ca} / \mathrm{P}$ ratio specially $\mathrm{HPO}_{4}$ and $\mathrm{CO}_{3}$ groups. The XRD method shows that, there were changes in crystallinity, lattice parameters and crystal size due to the substitution of chromium contents. From DTA analysis, there is endothermic peak was observed. This peak was attributed to the dehydration processes. There is also an exothermic peaks observed in the sample which is attributed to the crystallization temperature. HA acts as a carrier for the $\mathrm{Cr}^{3+}$ ions, where the $\mathrm{Ca}^{2+}$ ions substituted by the $\mathrm{Cr}^{3+}$ ions.

\section{REFERENCES}

[1] Boanini, E., et al. (2010) Ionic substitution in calcium phosphate synthesized at low temperature. Acat Biomaterial, 6, 1882-1894. doi:10.1016/j.actbio.2009.12.041

[2] Fanovish, M.A., et al. (1998) Improvement of micro structure and micro hardness of hydroxyapatite ceramics by addition of lithium. Material Letters, 33, 269-272. doi:10.1016/S0167-577X(97)00115-8

[3] Atsuo, I., et al. (2002) Zinc releasing calcium phosphate for stimulating bone formation. Material Science and Engineeriing: $C, 22,22-25$.

[4] Boukha, Z., Kacimi, M., Figueiredo, J.L., Pereira, M.F.R., Faria, J.L. and Ziyad, M. (2007) Methane dry reforming on Ni loaded hydroxyapatite and fluoroapatite. Applied Catalysis A: General, 317, 299-309. doi:10.1016/j.apcata.2006.10.029

[5] Mabilleau, G., Filmon, R., Petrov, P.K., Baslé, M.F., Sabokbar, A. and Chappard, D. (2010) Cobalt, chromium and nickel affect hydroxyapatite crystal growth in vitro. Act Biomaterialia, 6, 1555-1560. doi:10.1016/j.actbio.2009.10.035

[6] Pang, Y.X. and Bao, X. (2003) Influence of temperature, ripening time and calcination on the morphology and crystallinity of hydroxyapatite nanoparticles. Journal of the European Ceramic Society, 23, 1697-1704. doi:10.1016/S0955-2219(02)00413-2

[7] Elliott, J.C. (1994) Structure and chemistry of the apatitesand other calcium orthophosphates. Elsevier, Amsterdam.

[8] Chantawong, V., Harvey, N.W. and Bashkin, V.N. (2003) Comparison of heavy metaladsorptions by thai kaolin and 
ballclay. Water, Air, \& Soil Pollution, 148, 111-125. doi:10.1023/A:1025401927023

[9] Saxena, S. and D'Souza, S.F. (2006) Heavy metal pollution abatement using rock phosphatemineral. Environment International, 32, 199-202. doi:10.1016/i.envint.2005.08.011

[10] Crosman, A., Gelbard, G., Poncelet, G. and Parvulescu, V.I. (2004) Oxidative dehydrogenation of propane over chromium-loadedcalcium-hydroxyapatite. Applied Catalysis A: General, 23, 264.
[11] Boucetta, C., Kacimi, M., Ensuqueb, A., et al. (2009) Oxidative dehydrogenation of propane over chromium-loaded calcium-hydroxyapatite. Applied Catalysis A: General, 356, 201-210.

[12] Beale, A.M., Grandjean, D., Kornatowski, J., Glatzel, P., De Groot, F.M.F. and Weckhuysen, B.M. (2006) Unusual coordination behavior of $\mathrm{Cr}^{3+}$ in microporous aluminophosphates. The Journal of Physical Chemistry B, 110, 716722. doi:10.1021/jp0531006 